Article

\title{
Using Multivariate Statistical Methods to Analyze High-Quality Bicycle Path Service Systems: A Case Study of Popular Bicycle Paths in Taiwan
}

\author{
Shinn-Jou Lin ${ }^{1, *}$, Guey-Shin Shyu ${ }^{2}$, Wei-Ta Fang ${ }^{3}$, and Bai-You Cheng ${ }^{1, *}$ (i) \\ 1 Graduate Institute of Environmental Resources Management, TransWorld University, Douliu City, \\ Yunlin County 64063, Taiwan \\ 2 Department of Tourism, Tungnan University, Shenkeng District, New Taipei City 22202, Taiwan; \\ gsshyu@mail.tnu.edu.tw \\ 3 Graduate Institute of Environmental Education, National Taiwan Normal University, \\ Taipei City 11677, Taiwan; wtfang@ntnu.edu.tw \\ * Correspondence: shinnjou@gmail.com (S.-J.L.); biyocheng@gmail.com (B.-Y.C.); \\ Tel.: +886-5-5370988 (ext. 2400) (S.-J.L.); +886-5-5370988 (ext. 8233) (B.-Y.C.)
}

Received: 28 June 2020; Accepted: 1 September 2020; Published: 2 September 2020

\begin{abstract}
Taiwan has promoted bicycle tourism for nearly 20 years, and the bicycle paths it has constructed throughout the island are diverse in design. In the present study, an evaluation scale for bicycle path sightseeing potential was devised with a focus on the overall service quality of the paths; 30 popular bicycle paths were analyzed using a field survey, with expert consultation on quantitative indicators, and a qualitative analysis entailing interviews with people regarding the bicycle paths. A multivariate statistical analysis was performed on the quality of the service systems for these paths. The results revealed that the quality of these service systems is influenced by four principal components, namely, landscape attractiveness, image management, bicycle-specific paths, and accessibility, for a total explanatory power of $76.21 \%$; the individual explanatory power of these components was $25.89 \%, 21.49 \%, 16.81 \%$, and $12.03 \%$, respectively. Bicycle path conditions, service maintenance, and cleanliness and bicycle specificity are required for future high-quality bicycle paths; diverse bicycle rental services and bicycle types, entrance visibility, and ecological introduction boards along paths are value-added factors to bicycle path quality.
\end{abstract}

Keywords: bicycle paths; multivariate statistical; service quality; sightseeing potential

\section{Introduction}

Governments worldwide currently promote green transportation through policies to reduce carbon emissions and protect the environment, a development that has become a crucial trend of new-generation urban planning [1-4]. Bicycle paths and road networks are indicators of sustainable urban development, and recreational bicycle sports and in-depth sightseeing have become global trends in bicycle use [4,5].

As non carbon-emitting vehicles, bicycles can be used to develop tourism for recreation and fitness as well as to promote ecotourism. Cyclists can experience the cultures and landscapes of travel destinations in depth and, thus, cycling is a popular means of transportation [2,4,6-8]. Therefore, the construction of accessible, high-quality, convenient, and distinctive bicycle paths is a key development project for all governments at the city and county levels to undertake. Bicycles enable tourists to sightsee in scenic areas and experience spiritual relaxation; therefore, bicycle paths have recreational and fitness functions. When high-quality bicycle paths are completed, they become popular tourist destinations [7]. The United Kingdom attracts 250 million bicycle tourists per year, and they 
contribute nearly $£ 500$ million in annual tourism revenue [4]. The extensive economic opportunities provided by sports and recreation industries have received attention and been actively promoted in Europe and the United States [3,6,7].

In Taiwan, participants in bicycle sports have increased annually. By the end of 2020, more than 3.1 million people are projected to be involved in bicycle sports. To provide people with recreational areas for health and leisure activities, central and local governments have constructed networks of bicycle paths throughout Taiwan to provide cyclists with high-quality and accessible cycling environments $[1,3,6,7]$. According to official statistics, by 2020, bicycle paths in Taiwan extend for a total length of $7000 \mathrm{~km}$. The proportion of bicycle paths to all vehicle roads is $16.2 \%$. Bicycle paths connect urban and rural areas, and environmentally friendly and energy-efficient bicycle sightseeing facilitates the development of local recreational activities. Taiwanese people can ride bicycles for in-depth sightseeing at travel destinations; in addition to enjoying the breeze, they attain spiritual satisfaction by experiencing human history and local cultures in this low-carbon activity that promotes lifestyles of health and sustainability (LOHAS) [6-10].

As local governments increase their attention on bicycle path construction, the improvements of path service quality and accessibility are paramount. In addition to reinforcing the maintenance of physical facilities, people's satisfaction with their experiences on bicycle paths is affected by intangible aspects of these paths, such as their integration with surrounding ecological environments, connections with traffic networks, availability of instructional facilities, and convenience of bicycle rentals. These elements all influence the frequency of bicycle path use [6].

We studied the 30 most popular bicycle paths in Taiwan. The statuses and facilities of the paths were examined, and their key dimensions were analyzed statistically. This study focused on the causal relationships between the unique features of each bicycle path and its popularity. Feedback regarding current and popular paths was used to compile guidelines for exceptional bicycle path construction. These guidelines form a reference for future bicycle path construction.

\section{History of Bicycle Tourism Development in Taiwan}

Governments worldwide, including that of Taiwan, have begun investigating approaches for improving the use of green vehicles in transportation and sightseeing for environmental protection and energy conservation. According to Lumsdon [11], in addition to transportation, bicycles can be used in sightseeing $[4,8]$. The relaxing experience of biking has caused new sightseeing activities to emerge.

In 1997, the first ring path for bicycle tours was completed in Taiwan. The 12-km path is located in Kinalaungan, Taitung, and it is integrated with a waterfront park and the mountainous landscape. The path has attracted more than 300,000 visitors per year because of its pastoral and cultural landscapes, facilitating the growth of the local tourism industry [7]. Accordingly, governmental units in Taiwan have begun to construct numerous bicycle path networks that are integrated with local cultural and landscape characteristics throughout Taiwan. Taiwan's Ministry of Transportation and Communications is executing the round-island bicycle path upgrade plan. The main agenda items are the construction of international bicycle routes and characteristic tourism activities, the development of localized and in-depth bicycle tourism, round-island bicycle road network optimization, and safety improvements. These paths are designed in accordance with the four characteristics of bicycle sightseeing: environmental friendliness, green industry, natural experience, and healthy recreation [7,12].

Many bicycle paths have been completed in Taiwan since 2000 and have become popular sites for leisure activities, contributing to the popularity of biking as a recreational activity in Taiwan. Therefore, the Taiwanese government has begun to develop a national bicycle path system. Recreational bicycle paths that connect township greenways have been planned to slowly construct local path networks, and round-island and regional road networks will be connected to facilitate regional and local tourism development as well as economic growth. With the core principle of stretching miles of bicycle paths and walkways, all the bicycle routes and walkway systems throughout Taiwan are gradually becoming integrated to improve their infrastructure. Since 2007, May has been designated as bicycle month to 
reinforce the promotion of cycling. Railway carriages in the Taiwan Railway System were renovated in 2009 to enable cyclists to carry their bicycles onto trains in coordination with bicycle sports development. In the same year, the YouBike bicycle rental system began trial operations in Taipei City. The entire system was officially launched in 2012; currently, 1.8 million bicycles are rented per year [13,14]. In Taipei and Kaohsiung, the two largest cities in Taiwan, the Mass Rapid Transit (MRT) systems allow passengers to carry their personal bicycles on trains. Various measures have been implemented to fully promote bicycle recreation in Taiwan. The Taipei City government included bicycle paths for commuting and leisure in its urban planning (Taipei City Vision 2041) [1]. A bicycle path was also constructed on the high riverbank along the river that cuts through Taipei City. This riverbank bicycle path has become a favorite LOHAS bicycle path among Taipei City residents [13]. In the subsequent 10 years, in coordination with the landscape modeling projects of each township, bicycle paths were constructed and extended to connect with scenic spots in their surrounding areas, forming bicycle path systems (shown as Table 1 and Figure 1). This design concept has become the main principle of bicycle path development; it involves providing people with recreational bicycle paths and expanding tourism activities in all regions, thereby diversifying travel itineraries for Taiwanese people [15].

Table 1. Planning and establishment of bicycle path systems in Taiwan.

\begin{tabular}{|c|c|c|c|}
\hline Category & Conditions & Subcategories & Description \\
\hline \multirow{3}{*}{1} & \multirow{3}{*}{$\begin{array}{c}\square \text { Part of the long-distance } \\
\text { bicycle path with a } \\
\text { length }>100 \mathrm{~km} \\
\square \text { Multiday bicycle travel } \\
\square \text { Connections with regional } \\
\text { networks } \\
\square \text { Leisure and recreation } \\
\square \text { Environmental education } \\
\square \text { Local transportation } \\
\square \text { One-day cycling } \\
\square \text { Outdoor education }\end{array}$} & Recreation & $\begin{array}{l}\text { Paths that encompass a wide range of areas and } \\
\text { connect coasts, mountains, waterfronts, communities, } \\
\text { neighborhoods, scenic areas, and national parks. } \\
\text { Class } 1 S\end{array}$ \\
\hline & & Commuting & $\begin{array}{c}\text { Systems and facilities for commuter bicycle paths must } \\
\text { be redesigned on the basis of current } \\
\text { transportation facilities. } \\
\text { Class } 1 \mathrm{~L}\end{array}$ \\
\hline & & Competitions & $\begin{array}{l}\text { Taiwan Tournament. } \\
\text { Class } 1 \mathrm{R}\end{array}$ \\
\hline \multirow{3}{*}{2} & \multirow{3}{*}{$\begin{array}{c}\square \text { Regional bicycle path } \\
5 \text {-100-km long } \\
\square \text { Multiday bicycle travel } \\
\square \text { Connections with regional } \\
\text { networks } \\
\square \text { Leisure and recreation } \\
\text { Environmental education } \\
\text { Local transportation } \\
\square \text { One-day cycling } \\
\square \text { Outdoor education }\end{array}$} & Recreation & $\begin{array}{l}\text { Mainly scenic spots and field scenery along routes. } \\
\qquad \text { Class } 2 S\end{array}$ \\
\hline & & Commuting & $\begin{array}{c}\text { Bicycle paths for recreation and commuting are a } \\
\text { crucial part of the entire sightseeing path network and } \\
\text { connect current routes with landscapes, park walkway } \\
\text { systems, embankments, riverways, main farm roads, } \\
\text { aqueducts, and abandoned railways. } \\
\text { Class 2L }\end{array}$ \\
\hline & & Competitions & $\begin{array}{l}\text { The most common cycling purpose in the city is health } \\
\text { and recreation rather than racing. } \\
\text { Class } 2 \mathrm{R}\end{array}$ \\
\hline \multirow{3}{*}{3} & \multirow{3}{*}{$\begin{array}{c}\square \text { Local bicycle paths 2-30-km } \\
\text { long } \\
\square \text { Multiday bicycle travel } \\
\square \text { Connections with regional } \\
\text { networks } \\
\square \text { Leisure and recreation } \\
\square \text { Environmental education } \\
\square \text { Local transportation } \\
\square \text { One-day cycling } \\
\square \text { Outdoor education }\end{array}$} & Recreation & $\begin{array}{l}\text { Routes mainly for specific attractions. } \\
\text { Class 3S }\end{array}$ \\
\hline & & Commuting & $\begin{array}{c}\text { Paths for commuters and local residents are typically } \\
\text { constructed on the basis of current } \\
\text { transportation facilities. } \\
\text { Class 3L }\end{array}$ \\
\hline & & Competitions & $\begin{array}{l}\text { Paths are too short and are typically used for outdoor } \\
\text { education for students or leisure activities for residents. } \\
\qquad \text { Class } 3 R\end{array}$ \\
\hline
\end{tabular}

Note: The main classification was based on the lengths of the island, regional, and local road networks; each category has different main functions, and secondary functions may be repeated. 


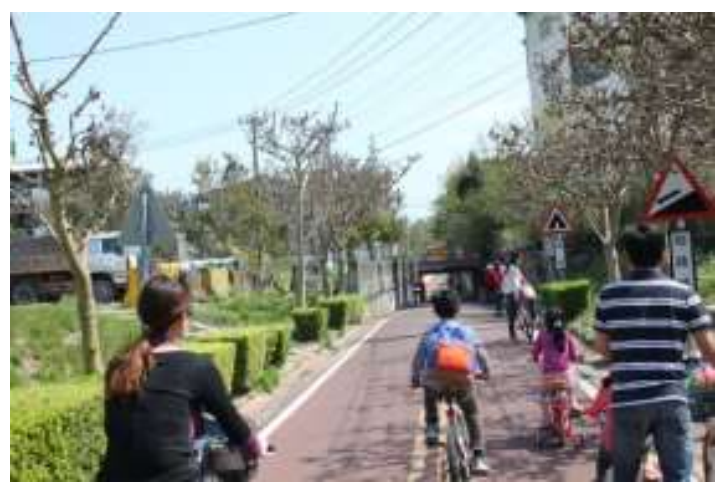

$(\mathbf{a})$

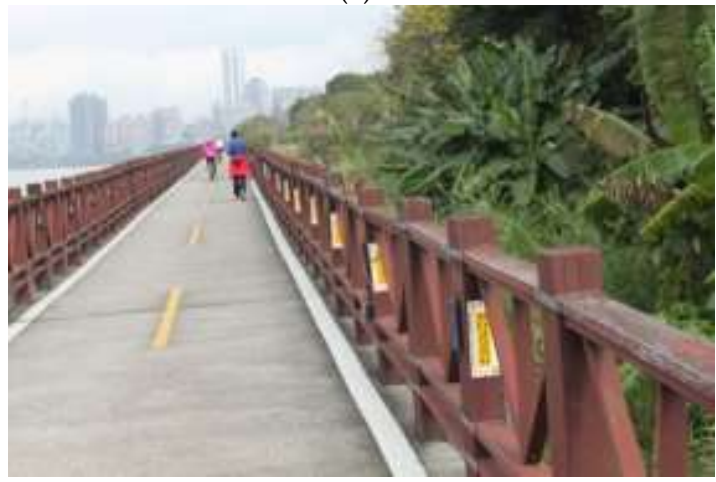

(c)

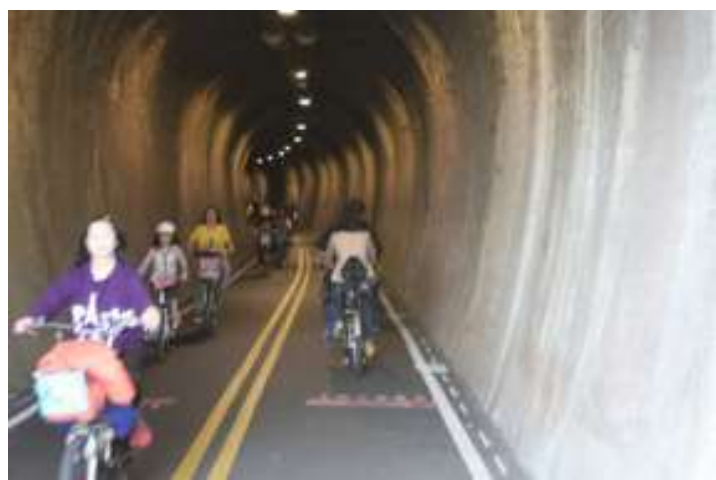

(b)

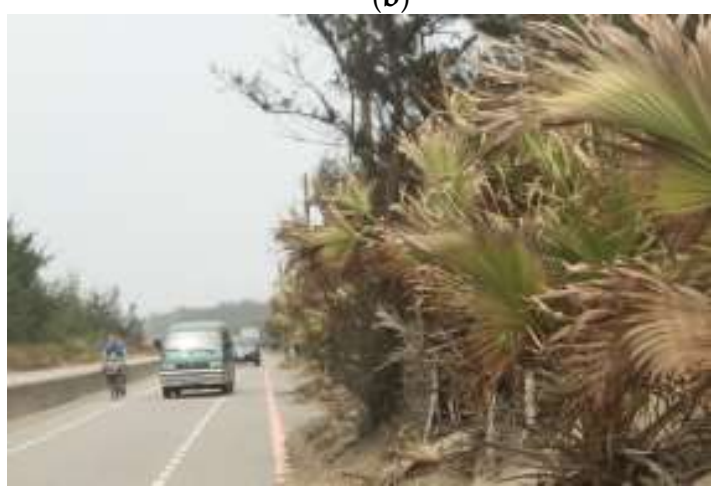

(d)

Figure 1. Several types of bicycle paths in Taiwan: (a) urban recreation and commuting, (b) tunne path, (c) riverside path, and (d) shared path.

Since the popularization of bicycle sightseeing, the bicycle industry has flourished. In the 1980s, Taiwan surpassed Japan in bicycle exports. By 2008, the international oil price had increased substantially (to a maximum of US $\$ 147.27 / \mathrm{barrel}$ ), and environmentalists advocated carbon reduction to save the earth; this increased worldwide attention on bicycle use [16]. By this time, Taiwan had exported a total of 5.40 million bicycles for a total sales volume of US $\$ 1.055$ billion, with the average unit price of a Taiwanese bicycle exported to Europe exceeding US \$200. Sponsorships and promotions by private enterprises and organizations, such as Tour de Taiwan (1987-1998), International Tour de Taiwan (1999), NeverStop (2007), Taiwan Cycling Festivals (2010), Taiwan Kom Challenges (2013), and personal long-distance biking challenges (e.g., $400 \mathrm{~km} / 27 \mathrm{~h}$ ) have also facilitated the increase in the cyclist population in Taiwan, reinforcing bicycle use. Several television dramas and movies have focused on the theme of bicycles, which has increased Taiwanese people's enthusiasm toward bicycle sports. People's intentions to purchase bicycles have significantly increased bicycle sales as well as demand for bicycle quality. According to a detailed survey by the Ministry of Transport and Communications (2016) in Taiwan, each household has an average of 1.24 bicycles. Taiwanese people are estimated to have 10.16 million bicycles; 460,000 electric bicycles; and 140,000 electric-assisted bicycles in total-in other words, people are willing to purchase high-quality bicycles at high prices, in turn facilitating the upgrading of the bicycle industry. The increase in the cyclist population also increased the sales and demand of peripheral bicycle-related products such as solar charging boards that enable cyclists to charge mobile phones or other electronic devices while cycling; solar-powered headlights provide lighting during night rides; and air cushion seat covers protect cyclists from buttock soreness when riding for long periods. Other popular bicycle-related products include safety helmets and driving recorders. The manufacturing and tourism industries related to bicycles have contributed substantial economic benefits. Giant, a major bicycle company in Taiwan, established a bicycle rental station at the Sun Moon Lake Visitor Center in 2009 to provide services related to bicycle recreation, 
thereby facilitating the widespread establishment of bicycle rental stations at popular recreational areas. Giant bicycle rental stations with 300 bicycles in total have been constructed next to the $30-\mathrm{km}$ bicycle path around the lake and approximately 26 rental companies, each with approximately 62 bicycles, operate in the surrounding areas. These rental companies provide 0.35 bicycles per person per day (10,731 visitors per day), and all bicycles can be rented twice daily.

Most relevant literature has focused on the sensory perceptions or environmental awareness of cyclists; moreover, only single bicycle paths have been examined in the research, and nearly no large-scale analyses have been conducted. The author investigated major bicycle paths in Taiwan on site from the perspective of a cyclist and with a focus on family-related functions. Suggestions were then provided regarding the planning and design of bicycle path systems.

\section{Materials and Methods}

\subsection{Research Materials}

We selected 30 popular cycling routes from lists of bicycle paths recommended by the general public, blogs, and the Tourism Bureau (Figure 2). The following two principals were applied for bicycle path selection:

1. Among popular bicycle paths discussed on the Internet, only highly recommended paths were selected.

2. The 30 selected bicycle paths needed to be distributed throughout the entire island of Taiwan; at least one path in each county was selected.

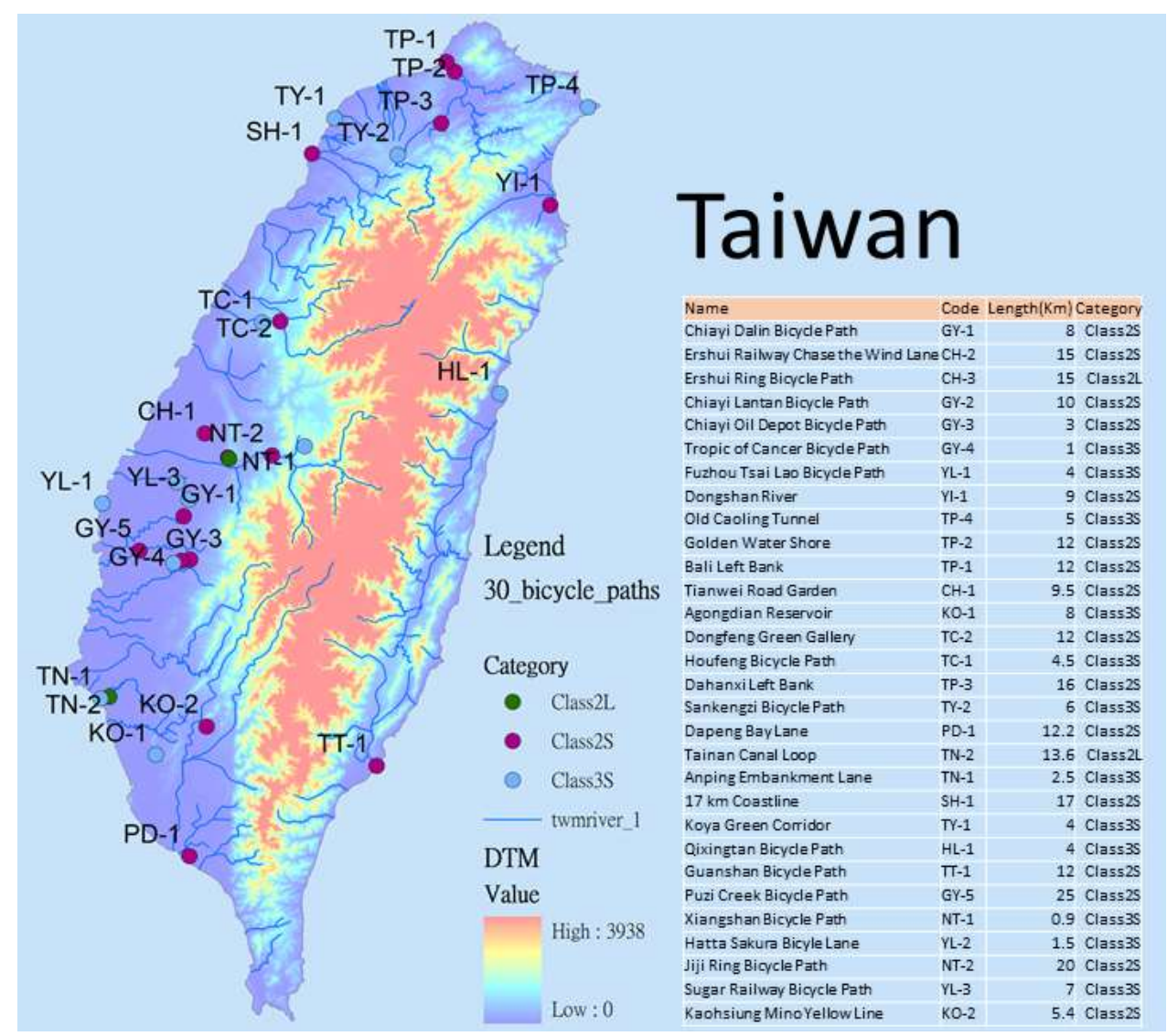

Figure 2. Thirty popular bicycle paths in Taiwan. 
Taiwan has approximately 52 popular bicycle paths. Therefore, 30 bicycle paths were selected on the basis of the aforementioned principles. We spent half of 2015 assembling a bicycle survey team of 10 professional cyclists to investigate and evaluate the paths on site.

\subsection{On-Site Investigation}

A field survey of the selected bicycle paths was performed through experiential riding and observation. All 10 professional cyclists participating in this study had at least five years of bicycle sightseeing experience. During the survey, road bicycles with global positioning systems were employed to record the bicycle paths, elevations, and slopes. The speed of the vehicles was maintained at $<10 \mathrm{~km} / \mathrm{h}$. We adopted the LOHAS travel approach to the on-site experience and observations of ecological systems, recreational attractions, service areas, and tourist service centers along the routes. Before travel, data were collected from path information published by tourism departments and websites for cycling enthusiasts. Overall traffic conditions and maps were thoroughly examined, and the actual biking experience and thoughts shared by cyclists in their blogs were referenced. The on-site survey was conducted on sunny or cloudy days but was halted on rainy days. The research team accompanied the investigators throughout the entire process. However, the researchers were (and are) not professional cyclists. After investigations were completed in each area, a meeting was held to determine all parameters, and the team members provided final approval of scores. All substantive topics were discussed in the meeting to identify survey topics. Finally, the team completed the scoring as well as scoping of the 30 popular bicycle paths. Quantitative research can assist in the understanding of an experience. However, to understand the reasons for experiences, we must engage in dialogue with our participants (i.e., the cyclists) and interpret their experiences. Therefore, we also conducted interviews to reduce potential inherent bias. In-depth interviews with 10 professional cyclists and five academic experts regarding six routes were conducted from March 2015 to September 2015. Several of the participants' comments are excerpted in Section 4.2.

\subsection{Establishing a Table Evaluating the Tourism Potential of Bicycle Paths}

The 10 professional cyclists and five academic experts formulated an evaluation table for the tourism potential of bicycle paths on the basis of a literature review [3,6,8,17-22]. The advantages and disadvantages of each path were examined according to the indices in the table. The table consisted of 11 quantitative evaluation items: whether the path is bicycle-specific, the main scenery, accessibility, availability of bicycle rental shops, path slope, path entrance visibility, path construction quality and scenery richness, route maps and markings, whether path and service areas are visible, parking convenience, and path integration with scenic sites. This uniform approach was used to simultaneously inspect various indices of the 30 bicycle paths. A slight sampling estimation problem occurred and was the main limitation of the quantitative analysis in this research. Therefore, qualitative interviews were added to reduce the inherent potential bias and support our final results.

After the survey, the 30 bicycle paths were scored on their conditions according to the tourism potential evaluation scale. Scores were calculated using a ridit analysis [23]. The maximum value of each parameter was 1 , and the minimum value was 0.2 . All parameters had the same evaluation interval.

\subsection{Multivariate Statistical Analysis}

Multivariate samples can be analyzed using various statistical methods such as factor analysis, which is primarily conducted to define latent dimensions. Dependent and independent variables are not defined in factor analysis; instead, a factor analysis calculates the correlation among all variables, yielding the optimal interpretation of all variables [24-27]. All variables undergo factor analysis to identify their correlations, thus enabling the summarization of all variables without excessive information loss. The variables are later named to become dimensions. After factor analysis, representative variables are selected. These variables retain most of the explanatory power as well as the original structures of the original variables; thus, data are reduced. The extracted principal 
factors, which originally do not belong to the data items, are the new variables organized from the data structure $[27,28]$. Therefore, these factors can be used to represent latent factors that seem ungeneralizable but exhibit considerable influence [29]. These factors supplement items that may have been overlooked or ungeneralizable in the analysis, thus, completing exploratory factor analysis. Cluster analysis involves the static classification of items with similar characteristics into groups or subsets; that is, each subset contains items with similar characteristics. Generally, data are clustered for unsupervised learning; these data are analyzed for convenient generalization and observation [30]. Cluster analysis was employed in this study to analyze the distribution of currently available types of bicycle sightseeing potential.

\section{Results}

\subsection{Evaluation of Sightseeing Potential of Primary Bicycle Paths in Taiwan}

\subsubsection{Scale Development for Calculating the Sightseeing Potentials of Bicycle Paths}

Table 2 lists the principles and scoring methods of the indices [23], which enabled professional bicycle investigators to evaluate bicycle paths using the same principles. After the investigation concluded, a group meeting was held to discuss the evaluation scores before final scores were confirmed. Any inconsistent opinions were discussed using the Delphi method for evaluation consistency [31].

Table 2. Description of indices and original ridit scores.

\begin{tabular}{ccc}
\hline Index & Name & Description \\
\hline Index1(V1) & Bicycle-specific paths & Yes (3); portions (2); shared with motor vehicles (1) \\
\hline Index2(V2) & Main scenery & From homogeneous or boring (1) to rich and varied (4). Higher scores indicate \\
richer scenery.
\end{tabular}

\subsubsection{Factor Analysis of Path Characteristics}

A correlation matrix calculation was performed on the 11 indices of the 30 bicycle paths (Table 3). The following seven variable pairs (correlation coefficients) reached the $p=0.05$ level of significance: V1-V5 (0.368), V1-V8 (0.388), V2-V7 (0.392), V2-V8 (0.424), V4-V8 (0.425), V6-V8 (0.439), and V7-V9 (0.407). The following 13 pairs reached the $p=0.01$ level of significance: V1-V2 $(0.481)$, V1-V7 (0.488), V2-V4 (0.591), V2-V10 (0.5), V2-V11 (0.364), V4-V10 (0.568), V4-V11 (0.604), V5-V7 (0.481), V6-V7 (0.503), V6-V9 (0.667), V7-V8 (0.684), V7-V9 (0.407), and V10-V11 (0.497). All other pairs had nonsignificant correlations. 
Table 3. Correlation coefficient matrix of the evaluation items.

\begin{tabular}{|c|c|c|c|c|c|c|c|c|c|c|c|}
\hline Item & V1 & V2 & V3 & V4 & V5 & V6 & V7 & V8 & V9 & V10 & V11 \\
\hline $\mathrm{V} 1$ & 1 & $0.481^{* *}$ & 0.051 & 0.299 & 0.368 * & 0.324 & $0.488^{* *}$ & 0.388 * & 0.264 & 0.033 & 0.000 \\
\hline $\mathrm{V} 2$ & & 1 & -0.160 & $0.591^{* *}$ & 0.162 & 0.113 & $0.392 *$ & 0.424 * & 0.079 & $0.500 * *$ & 0.364 * \\
\hline V3 & & & 1 & 0.155 & -0.023 & 0.117 & 0.169 & 0.290 & 0.134 & -0.175 & 0.257 \\
\hline $\mathrm{V} 4$ & & & & 1 & -0.167 & -0.084 & 0.111 & $0.425 *$ & 0.086 & $0.568^{* *}$ & $0.604^{* *}$ \\
\hline V5 & & & & & 1 & 0.044 & $0.481^{* *}$ & 0.027 & 0.137 & -0.015 & 0.010 \\
\hline V6 & & & & & & 1 & $0.503 * *$ & 0.439 * & $0.667^{* *}$ & -0.183 & -0.205 \\
\hline V7 & & & & & & & 1 & $0.684^{* *}$ & 0.407 * & 0.151 & 0.173 \\
\hline V8 & & & & & & & & 1 & 0.353 & 0.263 & 0.333 \\
\hline V9 & & & & & & & & & 1 & 0.024 & 0.035 \\
\hline V10 & & & & & & & & & & 1 & $0.497^{* *}$ \\
\hline V11 & & & & & & & & & & & 1 \\
\hline
\end{tabular}

Examining the service quality of a bicycle path by using only one variable does not enable the identification of a high-quality bicycle path's characteristics. The Kaiser-Meyer-Olkin coefficient of the variables was 0.652 , which was greater than 0.5 and confirmed the presence of latent principal factors. Therefore, factor analysis was performed to reduce the number of variables and generalize principal factors.

The total variance explained of the data was calculated, and components in the data were extracted. As presented in Table 4, when the eigenvalue of the unrotated component loading was $>1$, the four components had a total explanatory power of $76.21 \%$. The maximal explanatory power of the first, second, third, and fourth components was $32.36 \%, 21.24 \%, 12.75 \%$, and $9.87 \%$, respectively. When the eigenvalue of the rotated component loading was $>1$, the four components also had a total explanatory power of $76.21 \%$. The maximal explanatory power of the first, second, third, and fourth components was $25.89 \%, 21.49 \%, 16.81 \%$, and $12.03 \%$, respectively. This indicated a decrease in the difference between the variances explained. A slope chart was employed to examine the number of components extracted. The researcher subjectively determined a threshold value in the diagram. The number of components corresponding to the threshold value was defined as the most ideal number of components extracted. Because the eigenvalue of $>1$ was considered reasonable, four components were extracted in this study.

Table 4. Total variance explained.

\begin{tabular}{|c|c|c|c|c|c|c|c|c|c|}
\hline \multirow{2}{*}{ Component } & \multicolumn{3}{|c|}{ Initial Eigenvalues } & \multicolumn{3}{|c|}{$\begin{array}{c}\text { Extraction Sums of Squared } \\
\text { Loadings }\end{array}$} & \multicolumn{3}{|c|}{$\begin{array}{c}\text { Rotation Sums of Squared } \\
\text { Loadings }\end{array}$} \\
\hline & Total & $\begin{array}{l}\text { Variance } \\
(\%)\end{array}$ & $\begin{array}{c}\text { Cumulative } \\
(\%)\end{array}$ & Total & $\begin{array}{l}\text { Variance } \\
(\%)\end{array}$ & $\begin{array}{c}\text { Cumulative } \\
(\%)\end{array}$ & Total & $\begin{array}{l}\text { Variance } \\
(\%)\end{array}$ & $\begin{array}{c}\text { Cumulative } \\
(\%)\end{array}$ \\
\hline 1 & 3.559 & 32.357 & 32.357 & 3.559 & 32.357 & 32.357 & 2.848 & 25.888 & 25.888 \\
\hline 2 & 2.337 & 21.242 & 53.599 & 2.337 & 21.242 & 53.599 & 2.364 & 21.488 & 47.376 \\
\hline 3 & 1.402 & 12.747 & 66.345 & 1.402 & 12.747 & 66.345 & 1.849 & 16.812 & 64.188 \\
\hline 4 & 1.085 & 9.867 & 76.213 & 1.085 & 9.867 & 76.213 & 1.323 & 12.025 & 76.213 \\
\hline 5 & 0.800 & 7.271 & 83.484 & & & & & & \\
\hline 6 & 0.613 & 5.574 & 89.058 & & & & & & \\
\hline 7 & 0.363 & 3.303 & 92.361 & & & & & & \\
\hline 8 & 0.303 & 2.755 & 95.116 & & & & & & \\
\hline 9 & 0.217 & 1.974 & 97.090 & & & & & & \\
\hline 10 & 0.174 & 1.580 & 98.670 & & & & & & \\
\hline 11 & 0.146 & 1.330 & 100.000 & & & & & & \\
\hline
\end{tabular}




\subsubsection{Component Naming}

Table 5 lists the component loadings. Unrotated component loadings may exhibit a bicycle rental shops situation, which affects both components 1 and 2 and causes difficulties in explaining the components. Rotated component loadings enable strong explanations of each variable. Therefore, the components with rotated loadings were selected.

Table 5. Component matrix by 11 indices.

\begin{tabular}{lcccccccc}
\hline \multirow{2}{*}{ Indices } & \multicolumn{3}{c}{ Component Matrix ${ }^{\mathbf{a}}$} & \multicolumn{4}{c}{ Rotated Component Matrix ${ }^{\mathbf{b}}$} \\
\cline { 2 - 9 } & $\mathbf{1}$ & $\mathbf{2}$ & $\mathbf{3}$ & $\mathbf{4}$ & $\mathbf{1}$ & $\mathbf{2}$ & $\mathbf{3}$ & $\mathbf{4}$ \\
\hline Bicycle-specific paths & 0.634 & 0.256 & $\mathbf{- 0 . 3 4 2}{ }^{\mathrm{c}}$ & 0.081 & 0.221 & 0.376 & 0.627 & $\mathbf{- 0 . 0 0 8 5}$ \\
Main scenery & 0.713 & -0.330 & $\mathbf{- 0 . 3 6 5}$ & $\mathbf{- 0 . 1 6 3}$ & 0.739 & 0.178 & 0.362 & $\mathbf{- 0 . 2 6 2}$ \\
Accessibility & 0.209 & 0.121 & 0.714 & 0.556 & $\mathbf{- 0 . 0 3 1}$ & 0.133 & 0.001 & 0.927 \\
Bicycle rental shops & 0.620 & -0.612 & 0.168 & $\mathbf{- 0 . 1 0 0}$ & 0.874 & 0.081 & $\mathbf{- 0 . 0 6 4}$ & 0.147 \\
Path slope & 0.280 & 0.322 & $\mathbf{- 0 . 5 8 3}$ & 0.577 & $\mathbf{- 0 . 1 3 1}$ & $\mathbf{- 0 . 0 9 4}$ & 0.910 & 0.010 \\
Path entrance visibility & 0.452 & 0.697 & 0.197 & $\mathbf{- 0 . 3 8 4}$ & $\mathbf{- 0 . 1 6 0}$ & 0.918 & 0.088 & $\mathbf{- 0 . 0 2 2}$ \\
Path construction quality and & 0.767 & 0.386 & $\mathbf{- 0 . 1 2 1}$ & 0.200 & 0.196 & 0.537 & 0.658 & 0.178 \\
richness & & & & & & & & \\
Route maps and markings & 0.806 & 0.089 & 0.270 & $\mathbf{- 0 . 0 2 8}$ & 0.472 & 0.603 & 0.215 & 0.314 \\
Path and service area visibility & 0.496 & 0.498 & 0.234 & $\mathbf{- 0 . 3 0 8}$ & 0.005 & 0.798 & 0.066 & 0.058 \\
Parking convenience & 0.464 & -0.645 & $\mathbf{- 0 . 1 5 4}$ & $\mathbf{- 0 . 1 9 7}$ & 0.811 & $\mathbf{- 0 . 0 7 5}$ & $\mathbf{- 0 . 0 0 1}$ & $\mathbf{- 0 . 1 7 7}$ \\
Path integration with scenic sites & 0.487 & -0.602 & 0.264 & 0.280 & 0.725 & $\mathbf{- 0 . 1 4 4}$ & 0.031 & 0.448 \\
\hline
\end{tabular}

Note: ${ }^{\mathrm{a}}$ Extraction method: principal component analysis. Four components extracted. ${ }^{\mathrm{b}}$ Extraction method: principal component analysis. Rotation method: varimax with Kaiser normalization. Rotation converged in five iterations. ${ }^{\mathrm{c}}$ Bold type above absolute value 0.6 .

The indices of the first components were main scenery, presence of bicycle rental shops, parking convenience, and path integration with scenic sites; those of the second component were path entrance visibility, route maps and markings, and path and service area visibility; those of the third were path slope, construction quality, and richness; that of the fourth was accessibility.

The first component was named the landscape attraction component. A bicycle path with superior environmental conditions and integrated scenic sites provides plentiful recreation options; after it attracts sufficient tourists, industry owners have an incentive to provide services along the path. The second component was named the image management component, to which establishing path characteristics, providing clear route maps and markings, and increasing cyclist satisfaction were ascribed. The third component was the bicycle specificity component. Constructing bicycle-specific paths with variation in pavement and path designs can increase a sense of surprise and exploration in cyclists. The fourth component was the accessibility component. A bicycle path with easy access to railways and MRT systems has increased path convenience which contributes to the feasibility of low-carbon travel.

The top five items of the landscape attraction component were NT-1, TY-1, TP-1, TP-2, and TC-1. Many cyclists ride bicycles to experience nature. Therefore, the natural landscapes along a bicycle path and their beauty determine the attractiveness of a bicycle path. Bicycle paths with beautiful and diverse landscapes, in addition to attracting tourists, attract bicycle rental shops to provide services because of sufficient flows of tourists [1]; these shops provide not only bicycles for rental but also other diverse services such as parking spaces, maintenance and repair services, and consultations.

The top five items of the image management component were TP-4, GY-5, CH-2, TP-2, and GY-1, four of which focused on railway landscapes. This indicated that people favored currently used and abandoned railways or their surrounding environmental utilization.

The top five items of the bicycle specificity component were YI-1, KO-1, GY-3, KO-2, and TN-1. Bicycle paths designed to increase variable terrain and scenery while riding along routes were selected for cycling tourism, and these components can easily improve satisfaction in cycling. 
The top five items of the accessibility component were CH-3, NT-2, YI-1, CH-2, and TP-1. Bicycle paths neighboring train and MRT stations increase diverse and convenient options for low-carbon travel.

\subsection{Analysis of Interview Data}

By using observations and interviews with cyclists, we analyzed the conditions required for high-quality bicycle paths and their riding experiences, environmental knowledge, attitudes, and behaviors. We also recorded current relationships between cyclists and their riding circumstances. Our empirical data were gathered from oral records and participants' observations.

We asked interviewees to speak about our topics in interviews. We tried to conduct more discussions related to subjects of this study with cyclists in a certain period of time. We used the "Triangulation 2.0" concept as described by Denzin, who argued that "research is an interactive process shaped by the personal history, gender, [and] social class of the people in the setting." Final interviews with six people-three men aged 32-66 years and three women aged 16-43 years-were successfully recorded. Specifically, they were (1) TP0201, a 32-year-old male visitor with his own bike who was on his second journey; (2) TP0202, a male local resident aged 66 years who had his own bike and cycled every day; (3) CH0201, a male resident aged 41 years who had his own bike and cycles every week; (4) YL0101, a 16-year-old female visitor traveling with her family and renting a bicycle; (5) YL0102, the mother of YL0101, who was 43 years old and traveling with family with a rented bicycle; and (6) TT0101, a 42-year-old woman who was born in the local area but migrated to another town. She returned to her hometown every six months to visit her parents. She had her own bike and cycled once every half year. We asked participants three questions: (1) Why do you ride your bicycle here?, (2) What makes you happy while riding?, and (3) What areas do you think need improvement?

\section{Respondent TP0201:}

This bicycle path is very convenient. I take the MRT from Taipei City and rent a YouBike. It is very convenient. There are bicycle paths along the riversides around Taipei City, which is great. There are still some damaged places on the bikeways, which are a bit dangerous, and signs for some turns are not clear enough.

\section{Respondent TP0202:}

'The bike path near my home is a dedicated and long bicycle path. The scenery along the riverside is great. Pedestrians walk indiscriminately. However, there are too many people on holidays, and the bicycle paths are full of people, which is more dangerous.'

\section{Respondent CH0201:}

'I have hyperglycemia [high blood sugar] and need to exercise. This bike path between the county paths is suitable for cycling. The bikeway is specially designed with beautiful scenery in the fields, and there is a small pavilion where you can rest. However, the bikeway is not very clean. Puppies often sleep in the middle of the bikeway. Sometimes it is dangerous if you do not pay attention.'

\section{Respondent YL0101:}

'I came here to play with my family. The rice fields and flowers beside the bikeways are very fragrant and beautiful. However, the paths in some places merge with roads for motorcycles before the lanes change, which is dangerous.'

\section{Respondent YL0102:}

'This path was recommended by riders on the Internet; I just traveled here with my family to see the attractions. The bicycle paths are smooth, easy to navigate, and safe for children. However, the signs are not clear enough, which could be a dangerous situation if cyclists get lost.' 
Respondent TT0101:

'This is close to my home and a popular attraction. The quality of the bicycle path is very good, and it is well maintained. The scenery is beautiful, and the climate is cool. However, too many people crowd the path on holidays, there are barely any trash cans, and I get upset over unruly parking by cars.'

The survey team had many years of cumulative riding experience. During the survey, we not only employed substantive surveys but also used exchanges with local cyclists to facilitate follow-up on the overall evaluation. This survey not only used quantitative methods but also included qualitative components. We categorized high-quality bicycle path service systems into the following items: landscapes (respondents TP0201, TP0202, CH0201, YL0101, and TT0101); land quality (respondents TP0201, TP0202, CH0201, YL0102, and TT0101); path facility cleanliness (respondents TP0202 and CH0201); path entrance visibility (respondents TP0201, TP0202, and YL0101); and clear route maps, markings, and mileage markers (respondents TP0201, TP0202, YL0101, and YL0102). All respondents, especially respondent TP0201, agreed that diversity in bicycle rental systems and bicycle types for rental is crucial. In addition, the respondents suggested the following improvements for high-quality bicycle path service systems: bicycle-specific paths (respondents TP0202, CH0201, and YL0101), the introduction of ecological information (respondents CH0201 and YL0101), variability and creativity in path design (respondents TP0202, CH0201, and YL0102), and access to public transportation systems (respondent TP0201). These recommendations can be considered limitations of bicycle paths in terms of resource allocation, construction, and maintenance.

\subsection{Evaluation of Cluster Characteristic of Primary Bicycle Paths in Taiwan}

The components extracted from the factor analysis and their composition ratios were analyzed with the interview data in detail. Each bicycle path was influenced by four principal components, each of which may be affected by external conditions and cannot be improved [32]. To confirm the consistency of the final results, we used triangulation to avoid potential inherent bias [33]. In addition, a cluster analysis was conducted to divide the 30 paths into groups, and the basic conditions of each group were examined to identify viable measures for improving path quality. The cluster analysis enabled us to analyze the clustering of the paths assessed in the current study. The final results reveal the current situation of bicycle paths in Taiwan beyond their design alone. Therefore, by examining the inherent limitations of each type of path, we can customize the design enhancement method.

The results of the cluster analysis on the scores of each path on the four principal components were used to group paths with similar score distributions on the components (shown as Figure 3). A primary component of bicycle path popularity in Taiwan was countryside and natural landscapes (respondents TP0201, TP0202, CH0201, YL0101, and TT0101), which attract bicycle travel enthusiasts. CH-3 and YL-2 belonged to this component, which attracts people experienced in cycling. Another principal component was related to characteristic creation and required satisfactory service quality (respondents TP0201, TP0202, CH0201, YL0102, and TT0101), numerous tourists (respondent TP0202, and TT0101), government-reinforced path construction (respondents TP0201, TP0202, CH0201, YL0102, and TT0101), and a considerable flow of visitors during holidays (respondent TP0202, and TT0101). GY-3, GY-4, YL-3, YL-1, GY-1, KO-1, GY-5, CH-2, and TP-4 belonged to this component. The remaining principal components were composite components, which had varying scores that did not highlight any characteristic. All interview content was used to form conclusions. 


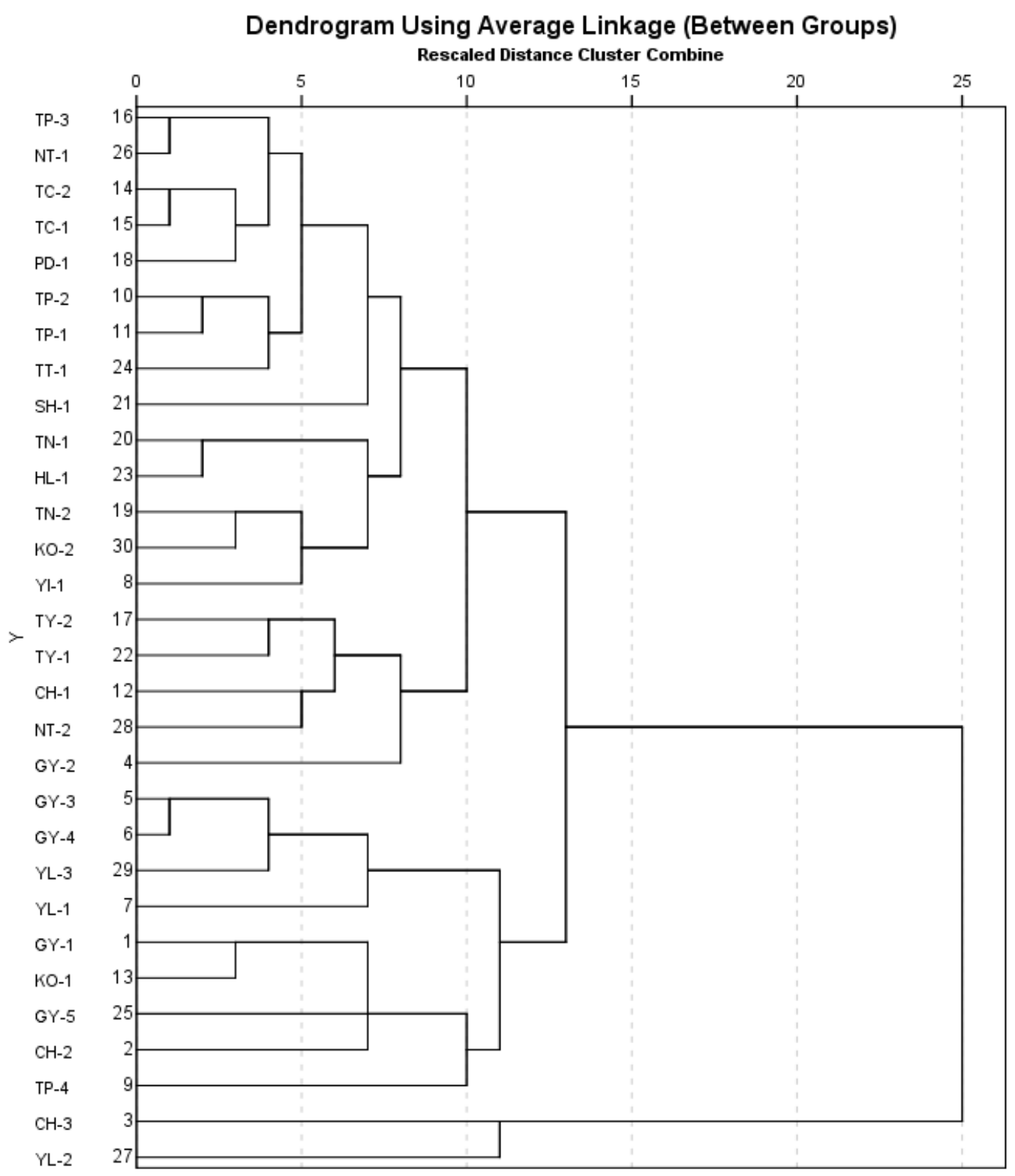

Figure 3. Cluster analysis of popular bicycle paths in Taiwan.

\section{Discussion}

This study developed essential value-added factors of high-quality bicycle path construction. According to the factor and cluster analyses, the following six essential factors were identified: (1) landscapes; (2) land quality; (3) path facility cleanliness; (4) path entrance visibility; (5) diversity in bicycle rental systems and bicycle types for rental; and (6) clear route maps, markings, and mileage markers. These six essential factors must be considered for each bicycle path service system. We also identified four value-added factors that should be considered in the construction of high-quality bicycle paths, namely, (1) bicycle specificity, (2) the introduction of ecological information, (3) variability and creativity in path design, and (4) access to public transportation systems. These factors can be considered to be limitations of bicycle paths in terms of resource allocation and their levels of construction and maintenance.

Essential factor 1-landscapes: Experiencing nature is crucial for many cyclists. All 30 bicycle paths selected in this study are popular because they are integrated with natural landscapes, such as 
mountains and lakes (e.g., Sun Moon Lake), coastlines (e.g., the Taiwan Strait), urban riverbanks (e.g., the Tamsui River), and the countryside (e.g., rice fields).

Essential factor 2-land quality: The bicycle paths in Taiwan are primarily composed of asphalt or cement pavement; some paths are composed of wooden pallets. Some sections of paths are shared by bicycles and motorcycles, which contribute to cyclist satisfaction. Although wooden paths are difficult to maintain because of the humid climate in Taiwan, all the paths selected in this study were considered to have satisfactory quality. These paths were well maintained because of their popularity.

Essential factor 3-path facility cleanliness: Maintained cleanliness among path facilities such as removing fallen leaves around pavilions and paths improves people's impressions of bicycle paths and their comfort in biking. Although bicycle paths with sufficient vegetation increase cyclist satisfaction, they are difficult to maintain because of numerous fallen leaves.

Essential factor 4-path entrance visibility: This includes the labeling of path names and the image of a bicycle that people can recognize on sight. Path TP-4 (with tunnels) features railway arts and folk songs at the entrance; Path TP-2 (coastline) features large wheel arts; Path SH-1 (with coastline) features fish, crabs, and bicycle arts. These represent the unique characteristics of individual bicycle paths.

Essential factor 5-diversity in bicycle rental systems and bicycle types for rental: Bicycle rental systems can involve either public or private rental shops. In addition to renting out bicycles, bicycle rental shops provide parking spaces, route consultation, and road rescue services. Popular bicycle paths feature multiple bicycle rental shops. Moreover, because many older adults or housewives require electric bicycles, which require less physical strength input to operate than conventional bicycles do, the establishment of bicycle rental shops is further justified [1]. Equipment provision and maintenance are the main functions of this factor.

Essential factor 6-clear route maps, markings, and mileages: Clearer information enables cyclists to ride bicycles with greater ease. Currently, the Taiwanese government plans to implement fifth-generation communication and real-time augmented reality information to further enhance the provision of path information to cyclists. Signage and information systems are the main functions of this factor.

Value-added factor 1-bicycle-path specificity: Bicycle-specific paths enable cyclists to ride safely with their families and with ease. This is beneficial to increasing cyclists' satisfaction and safety.

Value-added factor 2-ecological information introduction: Because of the rich ecology of Taiwan, many bicycle paths feature boards introducing the ecological environment; cyclists frequently use these boards to increase their knowledge, and they have suggested that additional boards be installed.

Value-added factor 3-variability and creativity of path designs: Vegetation on both sides of a bicycle path facilitates a sense of experiencing nature among cyclists. Additional creative design and ingenuity in different sections of the path can further enhance path design. Although path GY-1 is straight, some sections feature divisional or wavy designs. The path also features vine-shaped arches for an additional sense of novelty while biking.

Value-added factor 4-access to public transportation systems: Because of the convenience provided by the railway and highway networks in Taiwan, people frequently transport their bicycles to landscapes by car or train before riding to bicycle paths. Therefore, reinforced connections between bicycle paths and public transportation systems further encourage people to participate in low-carbon bicycle travel, enhancing the practice of green transportation.

\section{Conclusions}

Bicycle paths were evaluated through expert field surveys and data formulated through discussion. Because of the topography of Taiwan, its bicycle paths are diverse in design, reinforcing the representativeness of this study. The analyses revealed that factors related to landscape attraction [34], image management, bicycle specificity, and accessibility influence bicycle tourists' comfort and intentions to travel by bicycle. Favorable path conditions, path facility maintenance and cleanliness, and bicycle specificity are also crucial for high-quality bicycle paths. Diverse bicycle rental shop 
services and bicycle types for rental, along with path entrance visibility and boards introducing the ecological environment surrounding paths, can further contribute to the bicycle path quality.

Author Contributions: Data curation, S.-J.L. and G.-S.S.; Methodology, G.-S.S. and B.-Y.C.; Resources, S.-J.L.; Validation, W.-T.F.; Writing—original draft, B.-Y.C.; Writing—review \& editing, W.-T.F. All authors have read and agreed to the published version of the manuscript.

Funding: This research received no external funding.

Conflicts of Interest: The authors declare no conflict of interest.

\section{References}

1. Pai, T.J.; Pai, S.Y. User behaviour analysis of the public bike system in Taipei. Int. Rev. Spat. Plan. Sustain. Dev. 2015, 3, 39-52.

2. DeMaio, P. Bike-sharing: History, impacts, models of provision, and future. J. Publ. Transp. 2009, 12, 3. [CrossRef]

3. Lynch, A.J.; Andreason, S.; Eisenman, T.; Robinson, J.; Steif, K.; Birch, E.J. Sustainable Urban Development Indicators for the United States, Report to the Office of International and Philanthropic Innovation, Office of Policy Development and Research, US Department of Housing and Urban Development; Penn Institute for Urban Research: Philadelphia, PA, USA, 2011.

4. Ritchie, B.W. Bicycle tourism in the South Island of New Zealand: Planning and management issues. Tour. Manag. 1998, 19, 567-582. [CrossRef]

5. Suzuki, H.; Cervero, R.; Iuchi, K. Transforming Cities with Transit: Transit and Land-Use Integration for Sustainable Urban Development; The World Bank: Washington, DC, USA, 2013.

6. Chang, H.L.; Chang, H.W. Comparison between the differences of recreational cyclists in national scenic bikeway and local bike lane. J. East. Asia Soc. Transp. Stud. 2005, 6, 2178-2193.

7. Chang, H.W.; Chang, H.L. A strategic study of bicycle tourism in Taiwan. J. East. Asia Soc. Transp. Stud. 2003, 5, 1675-1685.

8. Cherry, C.; Cervero, R. Use characteristics and mode choice behavior of electric bike users in China. Transp. Policy 2007, 14, 247-257. [CrossRef]

9. Chang, S.J.; Chang, H.W.; Lee, Y.K. The status of cycling in Taiwan. In Bicycl. Asia; Tiwari, G., Arora, A., Jain, H., Eds.; Innovative Transport Solutions (iTrans), TBIU, Indian Institute of Technology Delhi, Transport Research \& Injury Prevention Programme (TRIPP): Delhi, India, 2008; pp. 27-48.

10. Urh, B. Lifestyle of Health and sustainability-the importance of health consciousness impact on LOHAS market growth in ecotourism. Quaestus 2015, 6, 167-177.

11. Lumsdon, L. Transport and tourism: Cycle tourism-a model for sustainable development? J. Sustain. Tour. 2000, 8, 361-377. [CrossRef]

12. Burbidge, S.K.; Goulias, K.G. Evaluating the impact of neighborhood trail development on active travel behavior and overall physical activity of suburban residents. Transp. Res. Rec. 2009, 2135, 78-86. [CrossRef]

13. Fang, W.-T.; Chang, H.-W.; Huang, Y.-W. Cycling recreation experiences and facilities: A case study of the Danshui riverside bike path, Taiwan. Int. J. Agric. Travel Tour. 2011, 2, 7-19.

14. Chen, S.Y.; Lu, C.C. A model of green acceptance and intentions to use bike-sharing: YouBike users in Taiwan. Netw. Spat. Econ. 2016, 16, 1103-1124. [CrossRef]

15. Chen, C.A.; \& Lee, H.L. How to promote bike tourism globally. Tour. Hosp. Manag. 2017, 23, 1-16. [CrossRef]

16. Chen, C.F.; Chen, P.C. Estimating recreational cyclists' preferences for bicycle routes-Evidence from Taiwan. Transp. Policy 2013, 26, 23-30. [CrossRef]

17. Virkler, M.R.; Balasubramanian, R. Flow characteristics on shared hiking/biking/jogging trails. Transp. Res. Rec. 1998, 1636, 43-46. [CrossRef]

18. Marion, J.L.; Leung, Y.F. Trail resource impacts and an examination of alternative assessment techniques. J. Park Recreat. Admn. 2001, 19, 17-37.

19. Stinson, M.A.; Bhat, C.R. Commuter bicyclist route choice: Analysis using a stated preference survey. Transp. Res. Rec. 2003, 1828, 107-115. [CrossRef]

20. de Dios Ortuzar, J.; Iacobelli, A.; Valeze, C. Estimating demand for a cycle-way network. Transp. Res. Part A Policy Pract. 2000, 34, 353-373. [CrossRef] 
21. Titze, S.; Stronegger, W.J.; Janschitz, S.; Oja, P. Association of built-environment, social-environment and personal factors with bicycling as a mode of transportation among Austrian city dwellers. Prev. Med. 2008, 47, 252-259. [CrossRef]

22. Dondi, G.; Simone, A.; Lantieri, C.; Vignali, V. Bike lane design: The context sensitive approach. Procedia Eng. 2011, 21, 897-906. [CrossRef]

23. Bross, I.D. How to use ridit analysis. Biometrics 1958, 14, 18-38. [CrossRef]

24. Harman, H.H. Modern Factor Analysis; University of Chicago Press: Chicago, IL, USA, 1976.

25. Cheng, B.-Y.; Shyu, G.-S.; Wu, S.-C.; Lin, H.-H.; Hsu, C.-H.; LePage, B.A.; Fang, W.-T. Fragmented Riverine Habitats in Taiwan Have Spatio-Temporal Consequences, Re-Distributing Caprimulgus affinis into Urban Areas Leading to a Human-Wildlife Conflict. Sustainability 2019, 11, 1778. [CrossRef]

26. Shyu, G.S.; Cheng, B.Y.; Chiang, C.T.; Yao, P.H.; Chang, T.K. Applying factor analysis combined with kriging and information entropy theory for mapping and evaluating the stability of groundwater quality variation in Taiwan. Int. J. Environ. Res. Public Health 2011, 8, 1084-1109. [CrossRef] [PubMed]

27. Holgado-Tello, F.P.; Chacón-Moscoso, S.; Barbero-García, I.; Vila-Abad, E. Polychoric versus Pearson correlations in exploratory and confirmatory factor analysis of ordinal variables. Qual. Quant. 2010, 44, 153. [CrossRef]

28. Yong, A.G.; Pearce, S. A beginner's guide to factor analysis: Focusing on exploratory factor analysis. Tutor. Quant. Methods Psychol. 2013, 9, 79-94. [CrossRef]

29. Hayton, J.C.; Allen, D.G.; Scarpello, V. Factor retention decisions in exploratory factor analysis: A tutorial on parallel analysis. Organ. Res. Methods 2004, 7, 191-205. [CrossRef]

30. Caliński, T.; Harabasz, J. A dendrite method for cluster analysis. Commun. Stat. Theory Methods 1974, 3, 1-27. [CrossRef]

31. Linstone, H.; Turoff, M. The Delphi Method Techniques and Application; Turoff, M., Linstone, H.A., Eds.; Addison-Wesley Educational Publishers Inc.: London, UK, 2002.

32. Newby, P.K.; Tucker, K.L. Empirically derived eating patterns using factor or cluster analysis: A review. Nutr. Rev. 2004, 62, 177-203.

33. Fang, W.-T. Envisioning Environmental Literacy: Action and Outreach; Springer Nature: Singapore, 2020 ; p. 53.

34. Fang, W.-T. Tourism in Emerging Economies: The Way We Green, Sustainable, and Healthy; Springer Nature: Singapore, 2020.

(C) 2020 by the authors. Licensee MDPI, Basel, Switzerland. This article is an open access article distributed under the terms and conditions of the Creative Commons Attribution (CC BY) license (http://creativecommons.org/licenses/by/4.0/). 